\title{
Effects of estragole on the compound action potential of the rat sciatic nerve
}

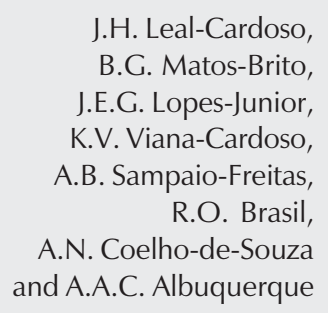

\author{
Centro de Ciências da Saúde, Universidade Estadual do Ceará, \\ Fortaleza, CE, Brasil
}

\author{
Correspondence \\ J.H. Leal-Cardoso \\ Centro de Ciências da Saúde \\ Universidade Estadual do Ceará \\ Av. Paranjana, 1700 \\ 60740-000 Fortaleza, CE \\ Brasil
}

Received February 18, 2003

Accepted April 27, 2004

\begin{abstract}
Estragole, a relatively nontoxic terpenoid ether, is an important constituent of many essential oils with widespread applications in folk medicine and aromatherapy and known to have potent local anesthetic activity. We investigated the effects of estragole on the compound action potential (CAP) of the rat sciatic nerve. The experiments were carried out on sciatic nerves dissected from Wistar rats. Nerves, mounted in a moist chamber, were stimulated at a frequency of $0.2 \mathrm{~Hz}$, with electric pulses of $50-100-\mu$ s duration at $10-20 \mathrm{~V}$, and evoked CAP were monitored on an oscilloscope and recorded on a computer. CAP control parameters were: peakto-peak amplitude (PPA), $9.9 \pm 0.55 \mathrm{mV}(\mathrm{N}=15)$, conduction velocity, $92.2 \pm 4.36 \mathrm{~m} / \mathrm{s}(\mathrm{N}=15)$, chronaxy, $45.6 \pm 3.74 \mu \mathrm{s}(\mathrm{N}=5)$, and rheobase, $3.9 \pm 0.78 \mathrm{~V}(\mathrm{~N}=5)$. Estragole induced a dose-dependent blockade of the CAP. At $0.6 \mathrm{mM}$, estragole had no demonstrable effect. At 2.0 and $6.0 \mathrm{mM}$ estragole, PPA was significantly reduced at the end of 180-min exposure of the nerve to the drug to $85.6 \pm$ 3.96 and $13.04 \pm 1.80 \%$ of control, respectively. At $4.0 \mathrm{mM}$, estragole significantly altered PPA, conduction velocity, chronaxy, and rheobase ( $\mathrm{P} \leq 0.05$, ANOVA; $\mathrm{N}=5$ ) to $49.3 \pm 6.21$ and $77.7 \pm 3.84$, $125.9 \pm 10.43$ and $116.7 \pm 4.59 \%$, of control, respectively. All of these effects developed slowly and were reversible upon a 300-min wash-out. The data show that estragole dose-dependently blocks nerve excitability.
\end{abstract}

Key words

- Estragole

- Essential oil

- Sciatic nerve

- Compound action potential

- Nerve conduction velocity
Estragole, a methyl chavicol and a relatively nontoxic volatile terpenoid ether, is a major component of the essential oil of many plants such as Ravensara anisata (Ravensara), Ocimum basilicum (basil), Foeniculum vulgare (fennel), Artemisia dracunculus (tarragon), and Croton zehntneri ("canela de cunhã”, in Northeastern Brazil), which are widely used in folk medicine and in aromatherapy $(1,2)$. Many biological actions of terpenoid ethers have been studied. The compounds are reported to have neurotropic, antimicrobial, antispasmodic, and immunostimulant properties $(2,3)$. Estragole 
and its isomer anethole have a documented sedative and anticonvulsant activity related to their neurotropic property $(2,3)$.

Many essential oils and their chemical constituents are known to have potent local anesthetic activity (4-6) and the blockade of neuronal excitability induced by them might have important inflammatory and immunological consequences $(7,8)$. Since no previous pharmacological studies with estragole have examined its effects on peripheral nerve electrophysiology, the objective of the present study was to characterize the actions of estragole on the compound action potential (CAP).

Sciatic nerves were dissected from Wistar rats (Rattus norvegicus, 300-350 g) sacrificed by cervical dislocation and exsanguination. All animals were cared for in compliance with the Guide for the Care and Use of Laboratory Animals, published by the US National Institute of Health (NIH Publication 85-23, revised 1985). One nerve was mounted in a moist chamber and one of its ends was stimulated with a stimulus isolation unit (Model SIU4678, Grass Instruments Co., Quincy, MA, USA) connected to a stimulator (Model S48, Grass Instruments Co.). Stimuli were delivered at a frequency of $0.2 \mathrm{~Hz}$, with electric pulses of $50-100-\mu \mathrm{s}$ duration at 10-20 V, for peak-to-peak amplitude and conduction velocity measurements and of 20-1000 $\mu$ s at 2-10 V for chronaxy and rheobase measurements. Evoked CAP were recorded with platinum electrodes placed 4 to $5 \mathrm{~cm}$ from the stimulating electrodes. For continuous monitoring these were connected to an oscilloscope (Model 547, Tektronix, Inc., Portland, OR, USA) through a high input impedance amplifier (Model P15, Grass Instruments Co.). For data capture and analysis, a digidata 1200 computer acquisition hardware (Axon Instruments, Inc., Foster City, CA, USA) and AxoScope software (Axon Instruments, Inc.) were used. A 15 - to $20-\mathrm{mm}$ segment of the nerve suspended between the stimulating and record- ing electrodes was immersed in Locke's solution which was used to maintain chamber humidity. Conduction velocity was measured by dividing the distance between the stimulating and recording electrodes by the time elapsed between the initiation of the stimulus and the time when $50 \%$ of the increase of the $\alpha$ component of CAP was reached. Strength-duration curves with constant-voltage square waves were used to determine rheobase and chronaxy (9). Rheobase was measured as the threshold stimulus voltage $\left(\mathrm{V}_{\mathrm{th}}\right)$ for an active response with a long-duration pulse $(1000 \mu \mathrm{s})$ and chronaxy as the pulse-width corresponding to twice the rheobase. Pharmacological agents were dissolved in Locke's solution and administered via the bath.

Before exposure to the drugs, the nerves were allowed to stabilize until stable peak-topeak CAP amplitude recording was achieved for at least $30 \mathrm{~min}$. The bathed nerve segment was then exposed to the pharmacological agent for $180 \mathrm{~min}$. This interval was usually sufficient to allow steady state action potential amplitude to be reached during estragole administration. This period was followed by wash-out and a 180-min recovery period. Experiments were carried out at room temperature $\left(24^{\circ}-26^{\circ} \mathrm{C}\right)$.

Modified Locke's solution $(140 \mathrm{mM} \mathrm{NaCl}$, $5.6 \mathrm{mM} \mathrm{KCl}, 2.2 \mathrm{mM} \mathrm{CaCl}_{2}, 1.2 \mathrm{mM} \mathrm{MgCl}_{2}$, $10 \mathrm{mM}$ glucose, and $10 \mathrm{mM}$ Tris-(hydroxymethyl-aminomethane), $\mathrm{pH}$ 7.4) was thoroughly aerated before use in the chamber. Nerves were usually employed on the day of dissection; however, in some experiments they were stored overnight in cold $\left(5^{\circ} \mathrm{C}\right)$ Locke's solution for use the following day. This storage period did not affect electrophysiological control parameters of the nerves.

An estragole stock solution (vehicle, dimethylsulfoxide, DMSO) prepared daily was added to the chamber Locke's solution so as to provide the desired estragole concentration with a final vehicle concentration always 
lower than $0.25 \%(\mathrm{v} / \mathrm{v})$. At this concentration DMSO did not alter CAP parameters. All salts and drugs, including estragole, were purchased from Sigma (St. Louis, MO, USA), or Reagen (Rio de Janeiro, RJ, Brazil) and were of analytical grade.

Results are reported as mean $\pm \mathrm{SEM}$, with $(\mathrm{N})$ indicating the number of experiments. Data were analyzed statistically by the Student $t$-test or by ANOVA followed by a contrast test, or a nonparametric test, as appropriate. Results were considered signifi- cant at $\mathrm{P} \leq 0.05$.

At $0.6 \mathrm{mM}$, estragole did not alter the CAP (Figure 1), but at doses of 2.0, 4.0 and $6.0 \mathrm{mM}$, peak-to-peak amplitude and conduction velocity were significantly reduced in a dose-dependent manner from control values $(9.9 \pm 0.55 \mathrm{mV}(\mathrm{N}=15)$ and $92.2 \pm$ $4.36 \mathrm{~m} / \mathrm{s}(\mathrm{N}=15)$, respectively). These effects developed slowly, as shown in Figure 1 , and were reversible. At the end of a 180min recovery period, with the use of 2.0, 4.0 and $6.0 \mathrm{mM}$ estragole, peak-to-peak ampli-

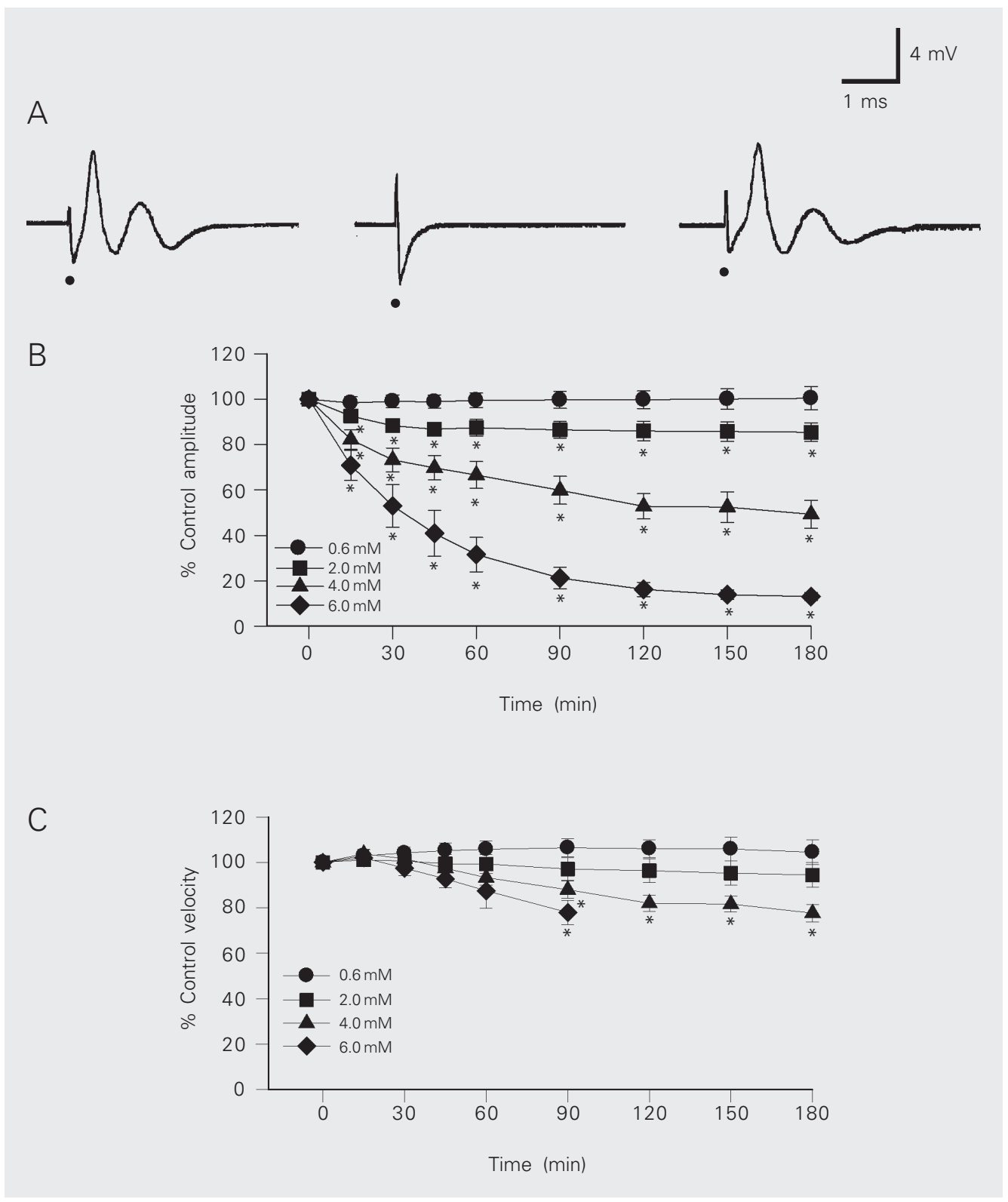

Figure 1. Time course of the effects of estragole on peak-topeak amplitude and conduction velocity of the compound action potential (CAP) of rat sciatic nerve. Panel A shows representative CAP tracings for control and at the 180th min of nerve exposure to $6.0 \mathrm{mM}$ estragole and at 180-min wash-out. The dot below each tracing (left side) shows the moment of stimulation. The quantification of the estragole-induced effect on peak-to-peak amplitude and conduction velocity is shown in panels $B$ and $C$, respectively. Data are reported as mean \pm SEM for 5 experiments. ${ }^{*} \mathrm{P}<$ 0.05 compared to control (ANOVA and Dunn's test). 
tude recovered to $110 \pm 3.42(\mathrm{~N}=5), 112.5$ \pm 9.02 and $127.29 \pm 11.67 \%$ of control $(\mathrm{N}=$ $5)$, respectively, and conduction velocity to $110.7 \pm 7.27(\mathrm{~N}=5), 94.2 \pm 3.00$ and 77.95 $\pm 5.30 \%$ of control $(\mathrm{N}=5)$.

Estragole $(4.0 \mathrm{mM})$ induced a reversible increase in $\mathrm{V}_{\text {th }}$ and chronaxy that was significant from the 30th to the 180th min of exposure to this substance $(\mathrm{P} \leq 0.05$, ANOVA and Dunnett's test). At $180 \mathrm{~min}$ of nerve exposure to $4.0 \mathrm{mM}$ estragole, $\mathrm{V}_{\text {th }}$ and chronaxy were $(\mathrm{N}=5) 116.7 \pm 4.59$ and $125.9 \pm$ $10.43 \%$, respectively, of control $(3.9 \pm 0.78$ $\mathrm{V}$ and $45.6 \pm 3.74 \mu \mathrm{s})$.

The major and novel result of the present study is that estragole blocks the compound action potential of the rat sciatic nerve. Estragole is a substance considered to be active on the central nervous system, with sedative and anticonvulsant activities $(2,3)$. Here we demonstrate that it also acts on peripheral nerves, reversibly depressing two parameters related to neuronal excitability, CAP peak-to-peak amplitude and conduction velocity. Estragole also increased $V_{\text {th }}$ and chronaxy, two parameters directly used to quantify nerve excitability (9). These alterations show that, within the concentration range used, estragole decreased neuronal excitability. Nerve $V_{\text {th }}$ and chronaxy changes might result from alteration of passive membrane properties (leakage conductivity and membrane time constant), voltage-dependent sodium conductance and geometric factors. In the present study we did not investigate the mechanism underlying the changes in excitability. Estragole is an isomer of anethole, for which important activities related to inflammatory and immunological processes have been described $(2,7)$, including blockade of all effects of tumor necrosis factor- $\alpha$ (10). Since the nervous system plays an important role in inflammation and immunity (8), it is important to characterize and elucidate the mechanism of action of estragole and anethole in terms of nerve effects, as done in the present study. The relevance of studies on the pharmacological activities of estragole is also supported by the similarity of its molecule to that of other important compounds. Estragole might be considered a derivative of eugenol, which has been widely used, via chemical synthesis, as a starting model in the search for new drugs (5,11-14).

Estragole has been previously shown to act on excitable tissues (15) with a profile of action that suggested a more potent inhibitory activity on nerve or neuromuscular transmission than on skeletal muscle fibers. This suggestion was based on the fact that, when used within the concentration range of 0.3 to $3.0 \mathrm{mM}$ in a neuromuscular preparation (phrenic nerve-diaphragm), estragol blocked the contractile muscle response to indirect (via nerve) stimulation, but not to direct muscle stimulation within a short period of observation (a few minutes). The results of the present investigation show that a significant inhibition of CAP only occurred at estragole concentrations $\geq 2 \mathrm{mM}$ and after a long time (tens of minutes) of nerve exposure (15). This suggests that the blockade of neuromuscular transmission previously reported was more likely to be an action on neuromuscular synapses rather than on nerves. The present data also agree with our previous preliminary report that at concentrations $\geq 5 \mathrm{mM}$ estragole blocks the CAP of toad peripheral nerves (16).

The effects of eugenol and some of its derivatives, such as terpineol, on CAP have been investigated $(4,17,18)$. All of these agents blocked the CAP of sciatic nerve with higher potency than demonstrated here for estragole.

It is known that many substances of the therapeutic arsenal, not considered to be local anesthetics, at concentrations higher than those minimally necessary for their specific effects might induce local anesthetic activity, as is the case, for instance, for $1 \mathrm{mM}$ atropine (19). The effective concentration range of estragole observed in the present study might seem high when compared to 
atropine, suggesting grossly nonspecific and irrelevant activity of estragole regarding CAP blockade. However, this seems to be unlikely for several reasons. First because, to the best of our knowledge, no other specific pharmacological effects of estragole have been described. Second, the effective concentration range of estragole for blockade of nerve excitability is similar to that of other classical local anesthetics such as procaine and lidocaine (20). Third, the activity of estragole on nerves is relevant when compared with that of other anesthetics. This is because a substance like lidocaine, for instance, within a millimolar concentration range and after long exposures (tens of minutes) did not block some CAP components related to certain sensory fibers (20). Compared to lidocaine, estragole fully blocks all CAP components, including those that are not completely blocked by lidocaine (data not shown). Thus, estragole compares favorably to lidocaine in terms of effective dose and blockade of sensory fibers.

Estragole blocked the amplitude and propagation velocity of CAP. The control values reported here for the two parameters used to quantify the action of estragole action on CAP, conduction velocity and peak-topeak amplitude, are well within the range reported by others in peripheral nerve recordings in vitro and in vivo. While reported conduction velocities ranged from 100 to 16 $\mathrm{m} / \mathrm{s}$ (18), our control value $(92.2 \mathrm{~m} / \mathrm{s})$ was close to the upper limit of this range, reflecting the condition of the nerves used. The preparation showed high and long-lasting (approximately $8 \mathrm{~h}$ ) stability, also confirming the high physiological quality of the preparations.

In conclusion, we have demonstrated that estragole, in the millimolar range, is active on nerves, having a depressive effect on excitability. This finding is relevant for the importance of estragole as a constituent of many essential oils used in aromatherapy (3).

\section{References}

1. Craveiro AA, Fernandes AG, Andrade CHS, Matos FJA, Alencar JW \& Machado MIL (1981). Óleos Essenciais de Plantas do Nordeste. Edições UFC, Fortaleza, CE, Brazil.

2. Franchome P \& Penoel D (1995). L'Aromathérapie Exactement: Encyclopedie de I'Utilisation Thérapeutique des Huiles Essentielles. Roger Jollois Edition, Limoges, France.

3. Tisserand R \& Balacs T (1995). Essential Oil Safety: A Guide for Health Care Professionals. Churchill Livingstone, New York.

4. Brodin P \& Roed A (1984). Effects of eugenol on rat phrenic-nerve diaphragm preparations. Archives of Oral Biology, 8: 611-615.

5. Dallmeier K \& Carlini EA (1981). Anesthetic, hypothermic, myorelaxant and anticonvulsant effects of synthetic eugenol derivates and natural analogues. Pharmacology, 22: 113-127.

6. Ghelardini C, Galeotti N, Salvatore G \& Mazzanti G (1999). Local anesthetic activity of the essential oil of Lavandula angustifolia. Planta Medica, 65: 700-703.

7. Oliveira AC, Leal-Cardoso JH, Santos CF, Morais SM \& Coelho-deSouza AN (2001). Antinociceptive effects of the essential oil of Croton zehntneri in mice. Brazilian Journal of Medical and Biological Research, 34: 1471-1474.

8. Elenkov IJ, Wilder RL, Chrousos GP \& Vizi ES (2000). The sympathetic nerve - an integrative interface between two supersystems: the brain and the immune system. Pharmacological Reviews, 52: 595-638.

9. Holsheimer JD, Dijkstra EA, Demeulemeester H \& Nutim B (2000). Chronaxy calculated from current-duration and voltage-duration data. Journal of Neuroscience Methods, 97: 47-50.

10. Chainy GBN, Manna SK, Chaturvedi MM \& Aggarwal BB (2000). Anethole blocks both early and late cellular responses transduced by tumor necrosis factor: effect on NF-кB, AP-1, JNK, MAPKK and apoptosis. Oncogene, 19: 2943-2950.

11. Ansher SS, Dolan P \& Bueding E (1986). Biochemical dithiolthiones. Food and Chemical Toxicology, 24: 405-415.

12. Stoof JA, Winogrodzka A, Vanmuiswinkel FL, Wolters EC, Voorn $P$, Groenewegen HJ, Booij J \& Drukarch B (1999). Leads for the development of neuroprotective treatments in Parkinson's disease and brain imaging methods for estimating treatment efficacy. European Journal of Pharmacology, 375: 75-86.

13. Huang $Y C$, Wu BN, Lin $Y T$, Chen SJ, Chiu CC, Cheng CJ \& Chen IJ (1999). Eugenodilol: a third-generation ß-adrenoceptor blocker, derived from eugenol, with $\alpha$-adrenoceptor blocking and $\beta 2$ adrenoceptor agonist-associated vasorelaxant activities. Journal of Cardiovascular Pharmacology, 34: 10-20.

14. Lin YT, Wu BN, Horng CF, Huang YC, Hong SJ, Lo YC, Cheng CJ \& Chen IJ (1999). Isoeugenolol: a selective $ß_{1}$-adrenergic antagonist with tracheal and vascular smooth muscle relaxant properties. Japanese Journal of Pharmacology, 80: 127-136.

15. Albuquerque AAC, Sorenson AL \& Leal-Cardoso JH (1995). Effects of essential oil of Croton zehntneri, and of anethole and estragole on skeletal muscle. Journal of Ethnopharmacology, 49: 41-49.

16. Albuquerque AAC, Xavier-Neto J, Diniz-Filho J, Viana GSB \& Leal- 
Cardoso JH (1984). Effects of essential oil of Croton Zehntneri, estragole and anethole on nerve and skeletal muscle. Revista de Medicina da Universidade Federal do Ceará, 24: 19-27.

17. Brodin P \& Roed A (1984). Inhibition by local anesthetic drugs at low and high stimulation frequencies: comparison between the isolated phrenic nerve of rat and the phrenic nerve-diaphragm preparation. Neuropharmacology, 23: 83-88.

18. Moreira MR, Cruz GM, Lopes MS, Albuquerque AA \& Leal-Cardoso $\mathrm{JH}$ (2001). Effects of terpineol on the compound action potential of the rat sciatic nerve. Brazilian Journal of Medical and Biological Research, 34: 1337-1340.

19. Bowman WC, Rand MJ \& West GB (1970). Drogas activas sobre los ganglios autónomos. In: Bowman WC, Rand MJ \& West GB (Editors), Farmacologia. Editorial Jims, Barcelona, Spain.

20. Potocnik I, Tomsic M \& Bajrovic F (2001). Sensitivity of sensory axons to lidocaine nerve block in rats. Pflügers Archiv, 442: R193R194. 